\title{
Republication: A Prospective Observational Study of Adoptive Immunotherapy for Cancer Using Zoledronate-Activated Killer (ZAK) Cells - An Analysis for Patients With Incurable Pancreatic Cancer
}

\author{
YOSHIYUKI YAMAGUCHI, YOUSUKE KATATA, MAKOTO OKAWAKI, \\ AKIRA SAWAKI and MASAHIRO YAMAMURA
}

Department of Clinical Oncology, Kawasaki Medical School and Hospital, Kurashiki, Okayama, Japan

\begin{abstract}
Background/Aim: Adoptive immunotherapy (AIT) using autologous zoledronate-activated killer (ZAK) cells has been performed for developing a novel modality of cancer treatment. In this study, data series from incurable pancreatic cancer were analyzed. Patients and Methods: Patients were treated with AIT using intravenous administration of ZAK cells every 3 to 4 weeks in combination with standard chemotherapy and possible clinical benefits were examined. Results: Seventy-five patients were treated. A median overall survival (OS) time of 6.7 months was achieved for all patients and 13.1 months for those treated 5 times or more, that increased to 14.6 and 18.3 months, respectively, when the previous treatment period of chemotherapy alone was included in the analysis. The disease control rate was $58.5 \%$. Multivariate regression analysis showed a significant positive correlation between the survival and baseline value of lymphocyte percentage in white blood cell counts $(p=0.031)$. Conclusion: The data suggest that AIT using
\end{abstract}

This article is freely accessible online.

Abbreviations: AIT, Adoptive immunotherapy; CD, cluster of differentiation; CR, complete response; DCs, dendritic cells; IL, interleukin; LAK, lymphokine-activated killer; OS, overall survival time; PBMC, peripheral blood mononuclear cell; PD, progressive disease; PR, partial response; QOL, quality of life; SD, stable disease; TIL, tumor-infiltrating lymphocyte; ZAK, zoledronateactivated killer.

Correspondence to: Yoshiyuki Yamaguchi, MD, PhD, Department of Clinical Oncology, Kawasaki Medical School and Hospital, Matsushima 577, Kurashiki, Okayama 701-0192, Japan. Tel: +81 864621111, Fax: +81 864641134, e-mail: shogo@med.kawasaki-m.ac.jp

Key Words: Adoptive immunotherapy (AIT), zoledronate, ZAK cells, $\gamma \delta \mathrm{T}$ cells, pancreatic cancer.
ZAK cells in combination with chemotherapy is safe and feasible and may be effective in prolonging survival for patients with incurable pancreatic cancer. The lymphocyte percentage at baseline may be a good biomarker for predicting the survival benefit of ZAK cell AIT.

In order to develop a novel modality of cancer treatment, we have been engaged in adoptive immunotherapy (AIT) trials using ex vivo-activated autologous lymphocytes, including lymphokine-activated killer (LAK) cells, tumor-infiltrating lymphocytes (TILs) and in vitro tumor-sensitized lymphocytes, since 1987 (1). Tumor responses have been limited with regard to quality of life (QOL) in locoregional administration for malignant effusion from gastrointestinal cancers (1), although other researchers have demonstrated survival benefits in hepatocellular carcinoma patients using postoperative LAK cell transfer (2) and in lung cancer patients using LAK cell transfer in combination with chemoradiotherapy (3). Thereafter, we introduced the use of dendritic cells (DCs) and tumor antigens into the effector cell generation system, although tumor responses were still limited (4).

Zoledronate, a bisphosphonate widely used to treat bone diseases, has been reported to stimulate anti-tumor effector lymphocytes with $\gamma \delta$-type $\mathrm{T}$ cell receptors in the presence of DCs (5). $\gamma \delta \mathrm{T}$ cells have been found to contain properties associated with the innate immune system, human leukocyte antigen (HLA)-unrestricted tumor recognition and high cytotoxic and proliferative potentials (6). Moreover, $\gamma \delta \mathrm{T}$ cells have been shown to possess an antigen-presenting function (7). We previously established a generation system for zoledronate-activated killer (ZAK) cells (8). Other researchers have reported trials of AIT using ZAK cells for patients with cancer and described its safety and feasible profiles $(9,10)$. Since 2009, we also have conducted a prospective observational study of AIT using ZAK cells for patients with various types of incurable cancers. 
In this study, we analyzed the cumulative data series from patients with advanced or metastatic pancreatic cancer and demonstrate the possible survival benefit of ZAK cell AIT in combination with standard chemotherapy. Furthermore, we identified a candidate biomarker to predict better prognosis in treating patients with incurable pancreatic cancer by ZAK cell AIT.

\section{Patients and Methods}

Study design. This treatment is a prospective observational study conducted at the Kawasaki Medical School Hospital between May 2009 and July 2014. All participating patient had a diagnosis of incurable pancreatic cancer with a performance status capable of visiting our outpatient clinic and provided informed consent. Patients with the following criteria were excluded: consecutive use of steroids or immunosuppressants, presence of autoimmune diseases, a case too difficult to manage at an outpatient clinic and/or uncontrolled complications. Participants were considered for study until deceased, withdrawal of consent or follow-up contact was lost. There were no protocol-specified treatments or assessments. All aspects of patients' treatments over time, including specific chemotherapy agents and/or combinations, as well as the dose, schedule and duration of AIT, were determined by a physician on a case-by-case basis. This prospective analysis was reviewed and approved by the Certified Committee for Regenerative Medicine of Kawasaki Medical School Hospital (Committee number, NB6150002; protocol number, PC6150017).

ZAK cell generation and transfer. Heparinized venous blood (10 $\mathrm{ml}$ ) was obtained from patients and the buffy coat and plasma were immediately separated by centrifugation $(2,000 \mathrm{rpm}, 30 \mathrm{~min})$. The buffy coat was re-suspended in RPMI-1640 medium and the suspension was layered on Lymphoprep (Muto Pure Chemicals, Tokyo, Japan). Peripheral blood mononuclear cells (PBMCs) were isolated by gradient centrifugation $(2,000 \mathrm{rpm}, 25 \mathrm{~min})$ and washed twice. ZAK cell generation has been mentioned in detail elsewhere (8). Briefly, PBMCs were re-suspended in the medium containing $2 \%$ heat-inactivated autologous plasma, $100 \mathrm{U} / \mathrm{ml}$ interleukin-2 (IL-2) (Sionogi, Osaka, Japan) and $1 \mu \mathrm{M}$ zoledronate (Novartis, Tokyo, Japan) at a density of $1 \times 10^{7} / \mathrm{ml}$. After incubation in a humidified atmosphere of $5 \% \mathrm{CO}_{2}$ for $24 \mathrm{~h}$ at $37^{\circ} \mathrm{C}$, cells $\left(2 \times 10^{6} / \mathrm{ml}\right)$ were transferred into new medium containing plasma and IL-2 but not zoledronate (complete medium (CM)), followed by further incubation for 10 to 14 days. CM was changed every 3 or 4 days. Cells were harvested by centrifugation, washed twice, re-suspended in $100 \mathrm{ml}$ saline after filtering through a $200-\mu \mathrm{m}$ mesh (Becton Dickinson Japan, Tokyo, Japan) and administered intravenously for 30 min every 3-4 weeks at a chemotherapy-off period. At each infusion, patients had blood drawn to prepare ZAK cells for the next transfer. Bacterial and endotoxin examinations were completed before each administration to make sure there was no contamination.

Clinical efficacy. Survival data of the patients were collected from patient records. If unknown, prognosis was requested by mail to the doctor-in-charge. Objective tumor response was evaluated by computed tomographic examinations. Data were collected at baseline (before ZAK cell AIT) and every 2 to 3 months. Complete
Table I. Patients enrolled in the AIT trial.

\begin{tabular}{lc}
\hline Total No. & 83 \\
Male/Female & $54 / 29$ \\
Age (median, range) & $64,35-83$ \\
Target and metastatic organs & \\
$\quad$ Liver & $43(52)$ \\
Pancreas & $21(25)$ \\
Lymph node & $18(22)$ \\
lung & $15(18)$ \\
Peritoneum & $11(13)$ \\
Bone & $2(2)$ \\
1 organ & $54(65)$ \\
$\geq 2$ & $19(23)$ \\
Concurrent treatments & \\
Chemotherapy & $64(77)$ \\
GEM & $28(34)$ \\
S-1 & $16(19)$ \\
GEM+S-1 & $14(17)$ \\
Others & $6(7)$ \\
None & $19(23)$ \\
\hline
\end{tabular}

Table II. Feasibility of AIT.

\begin{tabular}{lc}
\hline Total culture No. & 551 \\
Success of culture & $523(95.0 \%)$ \\
Phenotype (mean, range)(\%) & \\
CD3 & $86,69-97$ \\
$\gamma \delta T$ & $45,4-83$ \\
Administration No. & $11^{*}$ \\
0 & 31 \\
1 to 4 & 24 \\
5 to 9 & 12 \\
10 to 19 & 2 \\
20 to 29 & 3 \\
$\geq 30$ & $4(0-32)$ \\
Median (range) & \\
Total cell No. administered (mean) & $5.5 \times 10^{9}$ \\
All Pts treated & $9.7 \times 10^{9}$ \\
Pts treated $\geq 5$ times & 0 \\
Contamination detected & 0 \\
Endotoxin $>4.0$ &
\end{tabular}

*9, disease progression; 2, no lymphocyte growth.

response (CR), partial response (PR), stable disease (SD) and progressive disease (PD) were determined by the investigator according to the RECIST criteria (11).

Statistics. Statistical analysis was conducted using SPSS software (IBM Japan, Tokyo, Japan). Survival curves were drawn by KaplanMeyer analysis to estimate the median survival time (MST). Relationships between survival and hemato-chemical blood examination data were calculated with univariate and multivariate regression analysis. Values are presented as means \pm standard deviations and $p<0.05$ was defined as statistically significant. 


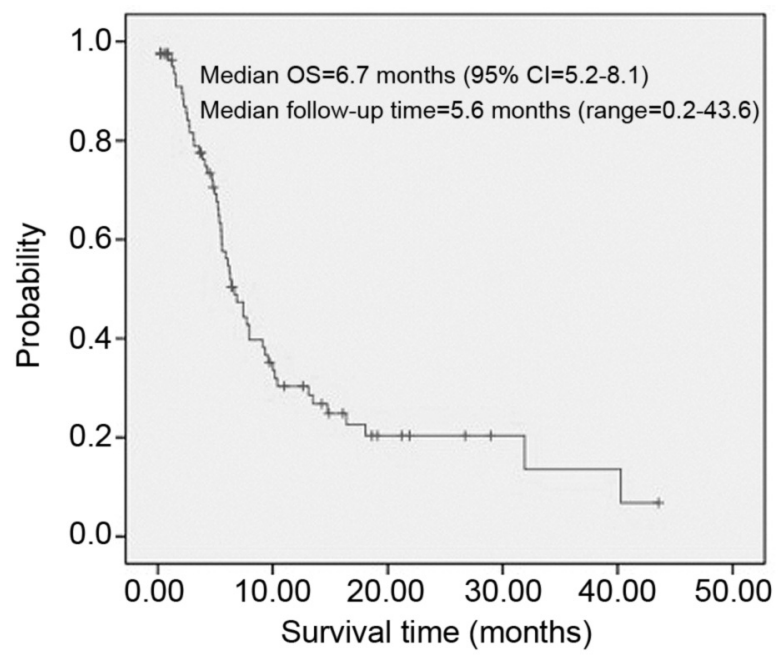

Figure 1. Overall survival of all patients enrolled. Survival curve was drawn by Kaplan-Meyer analysis to estimate median survival time (MST). OS, Overall survival; CI, confidence interval.

\section{Results}

Characteristics of enrolled patients. Eighty-six patients with pancreatic cancer were enrolled in this AIT trial using ZAK cells but 3 patients in the postoperative adjuvant setting were excluded from the analysis. The rest of the eighty-three patients included 54 males and 29 females with a mean age was 64, ranging from 35 to 83 years. Metastatic organs included the liver, lymph nodes, lung, peritoneum and bone; fifty-four patients had at least one metastatic site and 19 had 2 or more metastatic organs. Sixty-four patients received concurrent anti-cancer chemotherapy, the majority of which included gemcitabine (GEM), S-1 or their combination, as shown in Table I.

Feasibility of ZAK cell generation and transfer. Generation of ZAK cells was carried out 551 times in total and 523 cultures $(95.0 \%)$ were uneventful (Table II). ZAK cells contained $\gamma \delta \mathrm{T}$ cells in a mean value of $45 \%$ ranging from 4 to $83 \%$. Transfer of ZAK cells was completed once to 4 times for 31 patients, 5 to 9 times for 24,10 to 19 times for 12,20 to 29 times for 2 and $>30$ times for 3 patients; the median value was 4 times, including 11 patients who never received ZAK cell administration because of disease progression in 9 and no lymphocyte growth in 2 (Table II). The mean number of total cells transferred was $5.5 \times 10^{9}$ cells among all the treated patients and $9.7 \times 10^{9}$ cells among those treated more than 5 times. No detection of bacteria or endotoxin was evidenced in any of the cultures.

Survival analysis. Overall survival (OS) of all the patients treated is displayed in Figure 1, while survival analysis is summarized in Table III. With a median follow-up time of
Table III. Overall survival.

\begin{tabular}{lccc}
\hline & $\begin{array}{c}\text { Pts } \\
\text { No. }\end{array}$ & $\begin{array}{c}\text { MST } \\
\text { (months) }\end{array}$ & $\begin{array}{c}95 \% \mathrm{CI} \\
\text { (months) }\end{array}$ \\
\hline $\begin{array}{l}\text { AIT trial period } \\
\quad \text { All Pts }\end{array}$ & 83 & 6.7 & $5.2-8.1$ \\
$\quad \begin{array}{l}\text { Pts } \geq 5 \text { times } \\
\text { Considering previous }\end{array}$ & 41 & 13.1 & $7.7-18.5$ \\
treatment period & & & \\
$\quad$ All Pts & 83 & 14.6 & $12.4-16.7$ \\
$\quad$ Pts $\geq 5$ times & 41 & 18.3 & $17.0-19.6$ \\
\hline
\end{tabular}

Median follow-up time=16.6 months (range=0.7-43.5). AIT, Adoptive immunotherapy; MST, median survival time, CI, confidence interval; Pts, patients.

5.6 months (range $=0.2-43.6$ ), the median OS was 6.7 months (95\% confidence interval $(\mathrm{CI})=5.2-8.1)$ for all patients treated; this value increased to 13.1 months $(95 \% \mathrm{CI}=7.7$ 18.5) when limited to patients receiving more than $5 \mathrm{ZAK}$ cell AITs. Moreover, OS was prolonged to 14.6 months $(95 \%$ $\mathrm{CI}=12.4-16.7)$ for all treated patients and 18.3 months $(95 \%$ $\mathrm{CI}=17.0-19.6$ ) for patients with 5 or more administrations of ZAK cell AIT, when previous treatment periods of chemotherapy alone were added to the AIT period.

Tumor response. Tumor response is shown in Table IV. Of all the patients treated, 41 were evaluable for objective tumor responses. One $\mathrm{CR}$ and $1 \mathrm{PR}$ were recognized in 2 liver metastases, in whom S-1 was concomitantly administered with ZAK cells, resulting in a response rate of $4.8 \%$. Twenty-two patients $(53.7 \%)$ showed SD status, so that the disease control rate was estimated as $58.5 \%$.

Adverse events. Of 83 patients treated, 4 showed a temporary low-grade fever after ZAK cell administration. No other adverse events higher than grade 2 relevant to ZAK cell transfer were observed in any of the patients treated.

Analysis for patients with longer survival. The relationships between the survival and baseline (before ZAK cell AIT) clinical measurements were analyzed in an attempt to identify biomarkers for ZAK cell AIT benefit in patients with incurable pancreatic cancer. First, patients were divided into 2 groups, a longer-survival group and a shorter-survival group, and the clinical measures were compared between the two groups. A significantly higher lymphocyte percentage in white blood cells $(26.5 \pm 12.1 \%$ vs. $18.9 \pm 9.3 \% ; p=0.004)$ and lower level of C-reactive protein (CRP) $(0.6 \pm 0.9$ vs. $2.0 \pm 2.8 ; p=0.0304)$ were observed in the longer-survival group compared to the shorter-survival group (Table V). The serum albumin level tended to be higher $(3.7 \pm 0.6 v s .3 .4 \pm 0.6)$ in the longer- than 
Table IV. Objective responses after treatment with AIT.

\begin{tabular}{lcc}
\hline Response & No. of Pts & $\%$ \\
\hline CR & 1 & 2.4 \\
PR & 1 & 2.4 \\
SD & 22 & 53.7 \\
PD & 17 & 41.5 \\
Total & 41 & 100 \\
DCR $(C R+P R+S D)$ & 24 & 58.5 \\
\hline
\end{tabular}

AIT, Adoptive immunotherapy; Pts, patients; DCR, disease control rate; Not evaluated, 42 pts.

Table V. Comparison of baseline biochemical measures between pancreatic cancer patients with shorter ( $\leq 6.7$ months) and longer (> 6.7 months) survival times in ZAK cell AIT.

\begin{tabular}{lccc}
\hline $\begin{array}{l}\text { Measures } \\
\text { Value }\end{array}$ & Shorter & Longer & $p$ \\
& $(\mathrm{n}=36)$ & $(\mathrm{n}=36)$ & \\
\hline Cell No. at 1st administration & $9068 \pm 6852$ & $9145 \pm 6247$ & 0.9608 \\
Lymphocyte $(\%)$ & $18.9 \pm 9.3$ & $26.5 \pm 12.1$ & 0.004 \\
Lymphocyte count (/per $\mu \mathrm{l})$ & $1118 \pm 590$ & $1283 \pm 714$ & 0.297 \\
Albumin $(\mathrm{g} / \mathrm{dl})$ & $3.4 \pm 0.6$ & $3.7 \pm 0.6$ & 0.0958 \\
CRP $(\mathrm{mg} / \mathrm{dl})$ & $2.0 \pm 2.8$ & $0.6 \pm 0.9$ & 0.0304 \\
CEA $(\mathrm{ng} / \mathrm{ml})$ & $30.5 \pm 52.9$ & $15.8 \pm 26.5$ & 0.1487 \\
CA19-9 $(\mathrm{U} / \mathrm{ml})$ & $23192 \pm 77398$ & $3597 \pm 8073$ & 0.1468 \\
\hline
\end{tabular}

CRP, C-reactive protein; CEA, carcinoembryonic antigen; CA, carbohydrate antigen.

the shorter-survival group; however, the difference was not significant $(p=0.0958)$. Univariate regression analysis revealed that the survival was significantly correlated with the value of lymphocyte percentage $(\mathrm{cc}=0.353,95 \% \mathrm{CI}=0.129-0.543$, $p=0.0025$ ) (Figure 2) but not with that of lymphocyte number, serum albumin, CRP or tumor marker levels. Multivariate regression analysis was performed and showed a significant positive correlation between OS and lymphocyte percentage at baseline $(\mathrm{rc}=0.283,95 \% \mathrm{CI}=0.028-0.538, p<0.05, \mathrm{cc}=0.490)$ (Table VI).

\section{Discussion}

We have been conducting an observational study of AIT using ZAK cells in treating patients with incurable cancer since 2009. In this series, we rapidly accumulated more than 50 patients with pancreatic cancer, indicating that, among cancer patients, pancreatic cancer patients have been particularly pressed for treatment modalities, although novel chemotherapeutic regimens have been introduced more recently. Through the experience of more than 500 ZAK cell

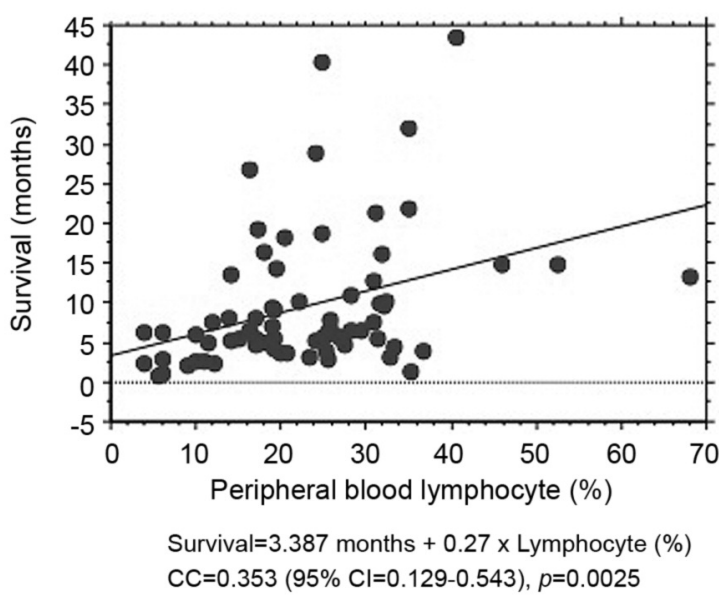

Figure 2. Univariate regression analysis between survival and the percentage of peripheral blood lymphocytes at the beginning of ZAK cell AIT. CC, Correlation coefficient; CI, confidence interval.

generations for pancreatic cancer patients, $95 \%$ cultures were uneventful with no contamination, indicating the safety and feasibility profile of our system in preparing ZAK cells. The finding that more transfers of ZAK cells may be more effective in treating pancreatic cancer patients suggests the need for a large-scale cell processing center at our hospital.

In this prospective observational study, the survival analysis implied the possible benefits of ZAK cell transfer in combination with conventional chemotherapy for incurable pancreatic cancer patients. Since 1997, GEM therapy has been the standard first-line treatment for patients with unresectable locally advanced or metastatic pancreatic cancer (12). In Japan, clinical trials of $\mathrm{S}-1$, an oral fluoropyrimidine derivative (Taiho Pharmaceutical, Tokyo, Japan), have been conducted since the early 2000s for patients with advanced and metastatic pancreatic cancer and S-1 has been approved for pancreatic cancer treatment. The present study was conducted under the above condition, where the chemotherapy regimens most commonly combined with ZAK cell AIT were GEM, S-1 and their combination. The GEST study (13), which was designed as phase III study on the relative benefits of GEM-alone, S-1 alone and GEM + S-1 with respect to OS, demonstrated median overall survivals of 8.8, 9.7 and 10.1 months, respectively, indicating that monotherapy with S-1 was not inferior to GEM in OS with good tolerability and presented a convenient oral alternative for locally advanced and metastatic pancreatic cancer and that GEM + S-1 was not statistically superior to gemcitabine alone. Our study showed a median overall survival time of 6.7 months for all pancreatic cancer patients treated and 13.1 months for those treated with 5 or more administrations of ZAK cell AIT, which increased to 14.6 and 18.3 months, respectively, when the previous 
Yamaguchi et al: Republication: AIT Using ZAK Cells for Incurable Pancreatic Cancer

Table VI. Multivariate regression analysis between survival and baseline (before ZAK cell AIT) biochemical measurements.

\begin{tabular}{lcccc}
\hline & RC & $95 \%$ CI & $p$-Value & CC \\
\hline Cell No. at 1st administration & $<0.001$ & - & 0.305 & 0.028 \\
Lymphocyte $(\%)$ & 0.283 & $0.028-0.538$ & 0.031 & 0.49 \\
Lymphocyte count $(/ \mu \mathrm{l})$ & $<0.001$ & $-0.004-0.003$ & 0.74 & 0.182 \\
Albumin $(\mathrm{mg} / \mathrm{dl})$ & 2.922 & $-1.311-7.155$ & 0.169 & 0.327 \\
CRP $(\mathrm{mg} / \mathrm{dl})$ & -0.262 & $-1.774-1.249$ & 0.725 & -0.394 \\
CEA $(\mathrm{ng} / \mathrm{ml})$ & -0.031 & $-0.113-0.051$ & 0.447 & -0.261 \\
CA19-9 $(\mathrm{lU} / \mathrm{m})$ & $<0.001$ & - & 0.582 & -0.26 \\
\hline
\end{tabular}

RC, Regression coefficient; CI, confidence interval; CC, correlation coefficient; CRP, C-reactive protein; CEA, carcinoembryonic antigen; CA, carbohydrate antigen.

treatment period of chemotherapy of GEM, S-1 or their combination was included in the calculation. These results imply a possible survival benefit of ZAK cell AIT over standard chemotherapy with GEM and/or S-1.

Recently, fluorouracil/leucovorin + irinotecan + oxaliplatin (FOLFIRINOX), a GEM-free combination regimen, demonstrated a clear survival benefit of 11.1 months compared with GEM (6.8 months) for patients with metastatic pancreatic cancer who had a performance status of 0 to 1 (14). More recently, nab-paclitaxel + gemcitabine significantly improved OS, PFS, and the response rate in patients with metastatic pancreatic cancer. It was reported that the median OS, the median PFS and the response rate were $8.5,5.5$ and $23 \%$ months, respectively, for nabpaclitaxel + gemcitabine treatment as compared with those of $6.7,3.7$ and $7 \%$ months, respectively, for GEM alone; all these data showed significant differences of $p<0.001$ (15). Considering these findings together, our survival data in this study may be of value for patients with pancreatic cancer. Kawaoka et al. reported that AIT using activated autologous lymphocytes stimulated by the MUC1expressing human pancreatic cancer cell line prolonged survival with reduced liver metastases after surgery (16), consistent with our results. Taken together, novel trials using ZAK cell AIT, in combination with recent standard chemotherapies, may also be warranted to address the efficacy of ZAK cell transfer for patients with unresectable or metastatic pancreatic cancer.

In contrast to the possible survival benefits, an objective tumor response was evident in only a few patients $(4.8 \%)$ treated with ZAK cells and chemotherapy. One possible explanation is that most patients $(77 \%)$ enrolled in our trial had already been treated with at least one or more chemotherapy regiments before ZAK cell transfer, making this observational study de facto a second-line setting. Another explanation may be an inherent property of immunotherapy. It has been reported that an objective tumor response was shown in only one of more than 300 prostatic cancer patients enrolled in a vaccine trial of sipuleucel-T (17), suggesting that immunotherapy may prolong survival without tumor shrinkage. Researchers in this field should pay more attention to the survival benefit of cancer immunotherapy.

We also sought adequate biomarkers to identify pancreatic cancer patients suitable for ZAK cell transfers. It was found, in our study, that patients with lymphocyte percentage more than $25 \%$ in white blood cells prior to ZAK cell AIT had longer survival than those with less than $25 \%$. Recently, the neutrophil-to-lymphocyte ratio (NLR) has been highlighted to be important as a prognostic biomarker in patients with many types of cancer. A lymphocyte percentage more than $25 \%$ in white blood cells means an NLR less than 3. Templeton et al. (18) reported that a high NLR (cut-off, 3 to 5 ) was associated with an adverse OS in many solid tumors and that the NLR was a readily available and inexpensive biomarker. In the recent nab-paclitaxel + gemcitabine study, NLR $>5$ at baseline was shown to be a marker of poor prognosis (19). One potential mechanism underlying the prognostic impact of NLR may be the association of high NLR with the chronic inflammatory condition of the host. It has been shown that neutrophilia, as an inflammatory response that may inhibit the immune system by suppressing the cytolytic activity of host immune cells, such as lymphocytes, activated $\mathrm{T}$ cells and natural killer cells (18), may also inhibit that of transferred ZAK cells. In relation to inflammation-based markers, it has been demonstrated that Glasgow prognostic score (GPS), consisting of serum albumin and CRP levels, can divide patients into three groups: patients with normal albumin $(\geq 3.5 \mathrm{~g} / \mathrm{dl})$ and normal CRP $(\leq 1.0 \mathrm{mg} / \mathrm{dl})$ as GPS 0 , those with low albumin $(<3.5 \mathrm{~g} / \mathrm{dl})$ or elevated CRP $(>1.0 \mathrm{mg} / \mathrm{dl})$ as GPS 1 and those with low albumin $(<3.5 \mathrm{~g} / \mathrm{dl})$ and elevated CRP (>1.0 mg/dl) as GPS 2, and that GPS 1 and 2 are independent predictors of poor patient outcome in treating gallbladder cancer (20). It has also been reported from data of 124 patients that NLR and GPS derived from routine blood 
tests can be used as clinically meaningful biomarkers to stratify advanced pancreatic cancer patients into different prognostic groups (21). In our study, patients with longer survival had a somewhat higher mean value of albumin (3.7 $\mathrm{g} / \mathrm{dl}$ ) and a significantly lower mean CRP $0.6 \mathrm{mg} / \mathrm{dl}$ when compared to the values of those with shorter survival $(3.4 \mathrm{~g} / \mathrm{dl}$ and $2.0 \mathrm{mg} / \mathrm{dl}$, respectively). Taken together, these data suggest that lymphocyte percentage in white blood cells or NLR, albumin and CRP levels at baseline may be good biomarkers not only for chemotherapy but also for immunotherapy in patients with incurable pancreatic cancer.

In conclusion, AIT using ZAK cells in combination with chemotherapy is safe and feasible and may be effective in prolonging survival for patients with incurable pancreatic cancer. The baseline lymphocyte percentage in white blood cells may be a good biomarker for survival benefit of this immunotherapy. Further prospective and comparative studies of ZAK cell AIT with standard chemotherapies are highly warranted to establish a more effective therapeutic regimen for patients with incurable pancreatic cancer.

\section{Republication Note}

The paper entitled "A Prospective Observational Study of Adoptive Immunotherapy for Cancer Using Zoledronate-Activated Killer (ZAK) Cells - An Analysis for Patients with Incurable Pancreatic Cancer" by Yamaguchi et al., has been originally published in Anticancer Research 36(5): 2307-2313, 2016, and was retracted by the Authors in July 2021. The retraction note was published in Anticancer Research 41(8): 4181, 2021. Because of the Authors' honest error regarding the study's approval number and since the underlying science is still valid, the article is republished with the following correction: On page 2308, line 20, the sentence "This prospective analysis was reviewed and approved by the central Institutional Review Board of Kawasaki Medical School (No. 1395, UMIN000021797)." is replaced by "This prospective analysis was reviewed and approved by the Certified Committee for Regenerative Medicine of Kawasaki Medical School Hospital (Committee number, NB6150002; protocol number, PC6150017).

\section{Conflicts of Interest and Source of Funding}

Y. Yamaguchi is currently receiving research expenses entrusted by the Okinawa Prefectural Government. Y. Yamaguchi has also received donations for research from Chugai Pharmaceutical Company, Yakult Honsha Company, Kyowa Hakko Kirin Company, Takeda Pharmaceutical Company, Daiichi Sankyo Healthcare Company, Ono Pharmaceutical Company, Taiho Pharmaceutical Company, BristolMyers Squibb and honoraria from Chugai Pharmaceutical Company. For the remaining authors, none were declared.

\section{Acknowledgements}

The Authors would like to thank Mrs. N. Okada, S. SAKUMA, T. Kurokawa, A. Tamura and Y. Nishiwaki for their special help with the tissue culture, as well as Mrs. K. Tokuda for her excellent management of the clinical data.

\section{References}

1 Yamaguchi Y, Ohshita A, Kawabuchi Y, Ohta K, Shimizu K, Minami K, Hihara J, Miyahara E and Toge T: Adoptive immunotherapy of cancer using activated autologous lymphocytes Current status and new strategies. Human Cell 16: 183-189, 2003. PMID: 15147038. DOI: 10.1111/j.1749-0774.2003.tb00152.x

2 Takayama T, Sekine T, Makuuchi M, Yamasaki S, Kosuge T, Yamamoto J, Shimada K, Sakamoto M, Hirohashi S, Ohashi Y and Kakizoe T: Adoptive immunotherapy to lower postsurgical recurrence rates of hepatocellular carcinoma: a randomised trial. Lancet 356: 802-807, 2000. PMID: 11022927. DOI: 10.1016/S0140-6736(00)02654-4

3 Kimura $\mathrm{H}$ and Yamaguchi Y: A phase III randomized study of interleukin-2 lymphokine-activated killer cell immunotherapy combined with chemotherapy or radiotherapy after curative or noncurative resection of primary lung carcinoma. Cancer 80: 4249, 1997. PMID: 9210707.

4 Yamaguchi Y, Ohta K, Kawabuchi Y, Ohshita A, Okita R, Okawaki M, Hironaka K, Matsuura K and Toge T: Feasibility study of adoptive immunotherapy for metastatic lung tumors using peptide-pulsed dendritic cell-activated killer (PDAK) cells. Anticancer Res 25: 2407-2415, 2005. PMID: 16080467.

5 Miyagawa F, Tanaka Y, Yamashita S, Mikami B, Danno K, Uehara $\mathrm{M}$ and Minato $\mathrm{N}$ : Essential requirement of antigen presentation by monocyte lineage cells for the activation of primary human gamma delta $\mathrm{T}$ cells by aminobisphosphonate antigen. J Immunol 166: 5508-5514, 2001. PMID: 11313389. DOI: $10.4049 /$ jimmunol.166.9.5508

6 Braza MS and Klein B: Anti-tumour immunotherapy with $\mathrm{V} \gamma 9 \mathrm{~V} \delta 2$ T lymphocytes: from the bench to the bedside. Br J Haematol 160: 123-132, 2013. PMID: 23061882. DOI: 10.1111/bjh.12090

7 Brandes M, Willimann K and Moser B: Professional antigenpresentation function by human gammadelta T Cells. Science 309: 264-268, 2005. PMID: 15933162. DOI: 10.1126/science.1110267

8 Nagamine I, Yamaguchi Y, Ohara M, Ikeda T and Okada M: Induction of gammadelta $\mathrm{T}$ cells using zoledronate plus interleukin-2 in patients with metastatic cancer. Hiroshima J Med Sci 58: 37-44, 2009. PMID: 19400555.

9 Sakamoto M, Nakajima J, Murakawa T, Fukami T, Yoshida Y, Murayama T, Takamoto S, Matsushita $\mathrm{H}$ and Kakimi K: Adoptive immunotherapy for advanced non-small cell lung cancer using zoledronate-expanded $\gamma \delta \mathrm{T}$ cells: A phase I clinical study. J Immunother 34: 202-211, 2011. PMID: 21304399. DOI: 10.1097/CJI.0b013e318207ecfb

10 Noguchi A, Kaneko T, Kamigaki T, Fujimoto K, Ozawa M, Saito M, Ariyoshi N and Goto S: Zoledronate-activated Vgamma9 gammadelta $\mathrm{T}$ cell-based immunotherapy is feasible and restores the impairment of gammadelta $\mathrm{T}$ cells in patients with solid tumors. Cytotherapy 13: 92-97, 2011. PMID: 20831354. DOI: $10.3109 / 14653249.2010 .515581$

11 Therasse P, Arbuck SG, Eisenhauer EA, Wanders J, Kaplan RS, Rubinstein L, Verweij J, Van Glabbeke M, van Oosterom AT, Christian MC and Gwyther SG: New guidelines to evaluate the response to treatment in solid tumors. EORTC, NCI US, NCI CA. J Natl Cancer Inst 92: 205-216, 2000. PMID: 10655437. DOI: $10.1093 /$ jnci/92.3.205

12 Burris HA III, Moore MJ, Andersen J, Green MR, Rothenberg ML, Modiano MR, Cripps MC, Portenoy RK, Storniolo AM, Tarassoff P, Nelson R, Dorr FA, Stephens CD and Von Hoff DD: 
Improvements in survival and clinical benefit with gemcitabine as first-line therapy for patients with advanced pancreas cancer: a randomized trial. J Clin Oncol 15: 2403-2413, 1997. PMID: 9196156. DOI: 10.1200/JCO.1997.15.6.2403

13 Ueno H, Ioka T, Ikeda M, Ohkawa S, Yanagimoto H, Boku N, Fukutomi A, Sugimori K, Baba H, Yamao K, Shimamura T, Sho M, Kitano M, Cheng AL, Mizumoto K, Chen JS, Furuse J, Funakoshi A, Hatori T, Yamaguchi T, Egawa S, Sato A, Ohashi Y, Okusaka T and Tanaka M: Randomized Phase III Study of Gemcitabine Plus S-1, S-1 Alone, or Gemcitabine Alone in Patients With Locally Advanced and Metastatic Pancreatic Cancer in Japan and Taiwan: GEST Study. J Clin Oncol 31: 1640-1648, 2013. PMID: 23547081. DOI: 10.1200/JCO.2012.43.3680

14 Conroy T, Desseigne F, Ychou M, Bouché O, Guimbaud R, Bécouarn Y, Adenis A, Raoul JL, Gourgou-Bourgade S, de la Fouchardière C, Bennouna J, Bachet JB, Khemissa-Akouz F, PéréVergé D, Delbaldo C, Assenat E, Chauffert B, Michel P, MontotoGrillot $\mathrm{C}$ and Ducreux M; Groupe Tumeurs Digestives of Unicancer; PRODIGE Intergroup: FOLFIRINOX versus gemcitabine for metastatic pancreatic cancer. N Engl J Med 364: 1817-1825, 2011. PMID: 21561347. DOI: 10.1056/NEJMoa1011923

15 Von Hoff DD, Ervin T, Arena FP, Chiorean EG, Infante J, Moore M, Seay T, Tjulandin SA, Ma WW, Saleh MN, Harris M, Reni M, Dowden S, Laheru D, Bahary N, Ramanathan RK, Tabernero J, Hidalgo M, Goldstein D, Van Cutsem E, Wei X, Iglesias J and Renschler MF: Increased Survival in Pancreatic Cancer with nabPaclitaxel plus Gemcitabine. N Engl J Med 369: 1691-1703, 2013. PMID: 24131140. DOI: 10.1056/NEJMoa1304369

16 Kawaoka T, Oka M, Takashima M, Ueno T, Yamamoto K, Yahara N, Yoshino S and Hazama S: Adoptive immunotherapy for pancreatic cancer: cytotoxic $\mathrm{T}$ lymphocytes stimulated by the MUC1-expressing human pancreatic cancer cell line YPK-1. Oncol Rep 20: 155-163, 2008. PMID: 18575732.
17 Kantoff PW, Higano CS, Shore ND, Berger ER, Small EJ, Penson DF, Redfern CH, Ferrari AC, Dreicer R, Sims RB, Xu Y, Frohlich MW and Schellhammer PF; IMPACT Study Investigators: Sipuleucel-T immunotherapy for castrationresistant prostate cancer. N Engl J Med 363: 411-422, 2010. PMID: 20818862. DOI: 10.1056/NEJMoa1001294

18 Templeton AJ, McNamara MG, Šeruga B, Vera-Badillo FE, Aneja P, Ocaña A, Leibowitz-Amit R, Sonpavde G, Knox JJ, Tran B, Tannock IF and Amir E: Prognostic role of neutrophilto-lymphocyte ratio in solid tumors: a systematic review and meta-analysis. J Natl Cancer Inst 106(6): dju124, 2014. PMID: 24875653. DOI: $10.1093 /$ jnci/dju124

19 Goldstein D, El-Maraghi RH, Hammel P, Heinemann V, Kunzmann V, Sastre J, Scheithauer W, Siena S, Tabernero J, Teixeira L, Tortora G, Van Laethem JL, Young R, Penenberg DN, Lu B, Romano A and Von Hoff DD: nab-Paclitaxel plus gemcitabine for metastatic pancreatic cancer: long-term survival from a phase III trial. J Natl Cancer Inst 107(2): dju413, 2015. PMID: 25638248. DOI: 10.1093/jnci/dju413

20 Shiba H, Misawa T, Fujiwara Y, Futagawa Y, Furukawa K, Haruki K, Iwase R, Iida T and Yanaga K: Glasgow prognostic score predicts outcome after surgical resection of gallbladder cancer. World J Surg 39: 753-758, 2015. PMID: 25348884. DOI: 10.1007/s00268-014-2844-0

21 Martin HL, Ohara K, Kiberu A, Van Hagen T, Davidson A and Khattak MA: Prognostic value of systemic inflammation-based markers in advanced pancreatic cancer. Intern Med J 44: 676682, 2014. PMID: 24750233. DOI: 10.1111/imj.12453

Received March 10, 2016

Revised April 11, 2016

Accepted April 12, 2016 